\title{
Impacts of the Covid-19 lockdown and relevant vulnerabilities on capability well- being, mental health and social support: an Austrian survey study
}

\author{
Judit Simon ${ }^{1,2^{*}}$, Timea M. Helter ${ }^{1}$, Ross G. White ${ }^{3}$, Catharina van der Boor ${ }^{3}$ and Agata Łaszewska ${ }^{1}$
}

\begin{abstract}
Background: Impacts of the Covid-19 pandemic and its public health measures go beyond physical and mental health and incorporate wider well-being impacts in terms of what people are free to do or be. We explored the impacts of the Covid-19 lockdown and relevant vulnerabilities on capability well-being, mental health and social support in Austria.

Methods: Adult Austrian residents $(n=560)$ provided responses to a cross-sectional online survey about their experiences during Covid-19 lockdown (15 March-15 April 2020). Instruments measuring capabilities (OxCAP-MH), depression and anxiety (HADS), social support (MSPSS) and mental well-being (WHO-5) were used in association with six pre-defined vulnerabilities using multivariable linear regression.

Results: $31 \%$ of the participants reported low mental well-being and only $30 \%$ of those with a history of mental health treatment received treatment during lockdown. Past mental health treatment had a significant negative effect across all outcome measures with an associated capability well-being score reduction of $-6.54(95 \% \mathrm{Cl},-9.26$, - 3.82). Direct Covid-19 experience and being 'at risk' due to age and/or physical health conditions were also associated with significant capability deprivations. When adjusted for vulnerabilities, significant capability reductions were observed in association with increased levels of depression $(-1.77)$ and anxiety $(-1.50)$, and significantly higher capability levels (+3.75) were associated with higher levels of social support. Compared to the cohort average, individual capability impacts varied between - 9\% for those reporting past mental health treatment and + $5 \%$ for those reporting one score higher on the social support scale.

Conclusions: Our study is the first to assess the capability limiting aspects of lockdown and relevant vulnerabilities alongside their impacts on mental health and social support. The negative capability well-being, mental health and social support impacts of the Covid-19 lockdown were strongest for people with a history of mental health treatment. Future public health policies concerning lockdowns should pay special attention to improve social support levels in order to increase public resilience.
\end{abstract}

Keywords: Covid-19, Austria, Capabilities, Well-being, Mental health, OxCAP-MH, Vulnerability, Resilience

\footnotetext{
* Correspondence: judit.simon@meduniwien.ac.at

'Department of Health Economics, Center for Public Health, Medical University of Vienna, Kinderspitalgasse 15, 1090 Vienna, Austria

2Department of Psychiatry, University of Oxford, Warneford Hospital, Oxford OX3 7JX, UK

Full list of author information is available at the end of the article
}

(c) The Author(s). 2021 Open Access This article is licensed under a Creative Commons Attribution 4.0 International License, which permits use, sharing, adaptation, distribution and reproduction in any medium or format, as long as you give appropriate credit to the original author(s) and the source, provide a link to the Creative Commons licence, and indicate if changes were made. The images or other third party material in this article are included in the article's Creative Commons licence, unless indicated otherwise in a credit line to the material. If material is not included in the article's Creative Commons licence and your intended use is not permitted by statutory regulation or exceeds the permitted use, you will need to obtain permission directly from the copyright holder. To view a copy of this licence, visit http://creativecommons.org/licenses/by/4.0/. The Creative Commons Public Domain Dedication waiver (http://creativecommons.org/publicdomain/zero/1.0/) applies to the data made available in this article, unless otherwise stated in a credit line to the data. 


\section{Introduction}

The recently discovered coronavirus, known as severe acute respiratory syndrome coronavirus 2 (SARS-CoV2 ), has spread globally within a span of a few months since December 2019 [1]. The Covid-19 disease caused by the virus was declared as a pandemic by the World Health Organisation (WHO) on 11 March 2020. Initial evidence suggested that the infection has a high effective reproduction rate with older populations and those with underlying health conditions being at high risk of severe disease and death, thereby forcing numerous countries into temporary lockdowns to limit the spread of the disease. Consequently, the Covid-19 pandemic went from a direct health emergency to a systemic crisis affecting people's lives in multiple ways [2]. Covid-19 impacts have been unprecedented because of its evolution from a health shock to a global economic and social crisis [2].

Substantial evidence from the past studies of the impacts of Severe Acute Respiratory Syndrome, Middle East Respiratory Syndrome, and Ebola epidemics on the suffering individuals and the healthcare providers showed substantial neuropsychiatric linkage [3]. There is an increasing amount of research related to the impacts Covid-19 on people's mental health and well-being [322]. Beside the direct health impact, public health emergencies may also affect individuals and communities through isolation, stigma, job insecurity, or inadequate resources for medical response [15]. These effects generate a range of emotional reactions, and can be particularly prevalent among those individuals who contract the disease, or those who are at increased risk due to their age or pre-existing medical conditions [15]. Evidence from previous pandemics shows that individuals who contracted the disease experienced fear, anxiety, emotional distress, and post-trauma stress symptoms [3]. The mental health/well-being impacts of the Covid-19 pandemic have been shown to be even more significant for those who are prone to psychological problems [6].

Impacts of the Covid19 pandemic and its public health measures go beyond physical and mental health and incorporate wider well-being impacts in terms of what people are free to do or be. Due to these complexities, the assessment of personal consequences related to wellbeing is challenging and may be best addressed within the conceptual framework of the capability approach introduced by Amartya Sen in the early 1980s [23]. The core focus of the capability approach is on what individuals are able to be and do in their lives, in other words, what they are capable of [23]. The capability approach provides a richer evaluative space beyond health and proposes that well-being is determined by people's freedom to engage in forms of being and doing that are of intrinsic value to the person [23]. Beside the recently proposed use of the capability framework in the understanding of policy challenges [24], this freedom aspect can be interpreted in the narrower mental health context as both the actual capabilities of a person, for instance, good mental health, and the processes that enable them, for instance, legal regulations [25]. Not only has the Covid-19 pandemic had a profound psychological impact, but it also affects personal freedoms to engage in behaviours that are consistent with subjectively held values beyond health, for instance, visiting loved ones, engaging in recreational activities, spending time outdoors. Despite these important links, the connection between pandemics and individual capabilities have not yet been researched.

In Europe, Austria stood out as a nation that adopted aggressive and early strategies and thereby saw a smaller proportion of deaths from Covid-19 compared to some other European countries [26]. The first Covid-19 case in Austria was reported on 25 February 2020 [27]. The Austrian government issued general laws to contain the epidemic by restricting social contacts and imposing strict lockdown measures from 16 March onwards [27] most of which have been lifted gradually since 15 April.

Early studies assessing the Covid-19 pandemic, and related public health measures, impacts found significant impact on the mental health of the Austrian population. The studies found that symptoms of moderate to severe anxiety and depression have tripled in Austria, and 8$13 \%$ of the population showed severe depression and 6$11 \%$ severe anxiety symptoms [28, 29].

The capability approach embodies a range of interlinking concepts and several studies have indicated that capability outcomes are strongly associated with mental health and social outcomes [30-34]. However, despite the increasing number of studies exploring the Covid-19 impact on mental health/well-being, information is still missing on the broader capability impact of the pandemic. Hence, this study aimed to explore the impact the Covid19 lockdown period on people's capabilities in association with mental health/well-being and social support, especially in the case of specific vulnerable groups in Austria. Covid-19 lockdown vulnerable groups were pre-defined as: (i) being categorised as 'at risk' group based on age and/or pre-existing physical health conditions; (ii) selfreported mental health treatment prior to the coronavirus pandemic; (iii) direct exposure to Covid-19 (having symptoms or being tested positive); (iv) indirect exposure to Covid-19 through a family member/friend; (v) having employment status impacted by the lockdown; or (vi) being categorised as critical worker.

\section{Methods}

\section{Study participants}

Participants were recruited using convenience sampling, i.e. the study sample consisted of people who responded 
to our survey advert. The advert was distributed via multiple channels including social media platforms (including Facebook, Twitter, WhatsApp) and emails targeting a wide range of individuals and organisations (universities, non-profit organisation such as Red Cross, and local governments) throughout Austria. In order to be able to participate in the study, respondents had to be older than 18 years, have sufficient German knowledge, and be residents in Austria at the time of the Covid-19 outbreak.

\section{Study design and data collection}

Cross-sectional data were collected via an online survey in May/June 2020, with all questions, including standardised outcome instruments, referring to the one-month lockdown period in Austria between 15 March and 15 April 2020.

The survey was developed in the SoSci online survey platform (Version 2), which is a publicly available tool and is free of charge for academic research [35]. The weblink of the survey was included in an advert, along with a QR code, that was circulated via social media platforms (including Facebook, Twitter, WhatsApp, etc.) and emails targeting a wide range of individuals and organisations throughout Austria.

Respondents who provided sociodemographic and Covid-19-related information and completed at least one standardised outcome instrument were considered for analysis. Those participants who discontinued the survey before fully completing at least one standardised outcome instrument were excluded from the analyses. The current analysis is based on the questions that were completed as part of the survey as outlined in the supplementary file (Supplementary file 1).

\section{Survey and instruments}

The online survey consisted of the participant information and consent forms followed by a section on sociodemographics. Subsequent sections assessed people's perceptions about the Covid-19 pandemic and the public health measures in place during the lockdown in Austria in response to the outbreak. The final part of the questionnaire consisted of four self-reported standardised and validated outcome instruments, which were used to assess capability well-being (OxCAP-MH), depression and anxiety levels (HADS), social support (MSPSS) and mental well-being (WHO-5) similar to a parallel linked survey in the UK [36]. The outcome instruments were adapted to the online survey including the adaptation of their introductory text reflecting the period of interest, i.e. the one-month lockdown period in Austria between 15 March and 15 April 2020.

The Oxford CAPabilities questionnaire-Mental Health (OxCAP-MH) instrument was developed by Simon et al. in 2013 [37]. It is specifically designed to capture different well-being dimensions within the capability framework in the area of mental health across 16 items. The OxCAP-MH is scored on a 0-100 scale, with higher scores indicating better capabilities. The OxCAP-MH has shown good psychometric properties including internal consistency (Cronbach's alpha between 0.79 and 0.85 ), test-retest reliability (intra class correlation coefficient 0.80 ), construct validity and responsiveness in both English and German populations [33, 34]. The German version of the OxCAP-MH [38] was obtained from the authors for the study.

The Hospital Anxiety and Depression Scale (HADS) was developed by Zigmond and Snaith in 1983 [39]. The questionnaire is divided into Anxiety (HADS-A) and Depression (HADS-D) subscales both containing seven items scored on a four-point scale from zero (not present) to three (considerable). Both the HADS-A and HADS-D subscales are scored from 0 to 21, with higher scores indicating higher anxiety or depression levels. Normal, borderline and abnormal anxiety/depression scores are defined as $0-7,8-10$ and $11-21$, respectively [39]. The HADS was found to perform well in assessing the presence and severity of anxiety disorders and depression in both somatic and psychiatric cases, also beyond the hospital setting, including the primary care patients and general population (mean sensitivity 0.90 and mean specificity 0.78 for a cut-off score of $8+$ for HADS-A; and mean sensitivity 0.83 and mean specificity 0.79 for a cut-off score of $8+$ for HADS-D) [40]. Cronbach's alpha coefficient of internal consistency reported in several studies varied from 0.68 to 0.93 for HADS-A and from 0.67 to 0.90 for HADS-D [40]. The German translation of HADS was obtained from Hogrefe Publishing Group.

The Multidimensional Scale of Perceived Social Support (MSPSS) is a self-reported measure of subjectively assessed social support developed by Zimet et al. in 1988 [41]. The questionnaire can be divided into three subscales, each addressing a different source of support: Family, Friends, and Significant Other. Low, moderate and high support are defined as $<3,3-5$ and $>5$, respectively [41]. The instrument has good internal consistency (Cronbach's alpha 0.88 ) and test-retest reliability (0.85) [41]. An official German translation of MSPSS was obtained from the developer of the original English version.

The World Health Organisation-Five Well-being Index (WHO-5) is a short self-reported measure of current mental well-being introduced in 1998 by the WHO Regional Office in Europe [42]. Respondents are asked to rate how well each of the five statements about positive well-being applied to them in the given period from 5 (all of the time) to 0 (none of the time). The WHO-5 is 
scored $0-25$, with higher scores representing higher well-being [43]. The WHO-5 has been used in multiple studies across countries and disease areas [43]. A review of 213 articles using the WHO-5 as an outcome measure confirmed that the instrument has satisfactory construct validity, responsiveness and it can be used as a screening tool for depression [43]. The German translation of the WHO-5 is available in the public domain without registration.

\section{Definition of vulnerabilities}

In the current study, six hypothesised associations between increased levels of mental health symptoms and decreased levels of well-being were tested according to pre-defined vulnerabilities identified as relevant to Covid-19: 1) "At risk" group; 2) Past mental health treatment; 3) Direct Covid-19 experience; 4) Indirect Covid19 experience; 5) Employment status affected by Covid19; and 6) Critical worker. Individuals were defined as 'at risk' if they were aged 65 years or over and/or had a self-reported underlying physical health condition including diabetes, heart/cardiovascular disease, stroke/ cerebrovascular disease, lung disease, liver disease, or cancer. Participants who reported mental health service use prior to the period of interest were categorised as 'having past mental health treatment'. Participants with 'direct Covid-19 experience' were those who tested positive for Covid-19 or experienced Covid-19 symptoms, but were not tested. 'Indirect Covid-19 experience' was defined as having a friend and/or family member infected or knowing someone who died of Covid-19. Participants with 'employment status affected' were those who reported losing their job due to the pandemic or being sent to short-time working (German 'Kurzarbeit'). Finally, participants who reported having a job categorised by the government as critical worker, e.g. healthcare staff, police officer or food supply worker, were defined as 'critical workers'.

\section{Statistical analysis}

Anonymous data were extracted from the online survey and checked for logical inconsistencies. Characteristics of the study cohort in comparison to the general Austrian population were presented.

Correlations between the different outcome measures were explored using Pearson's correlations and interpreted as small $<0.3$, moderate $0.3-0.49$, or large $\geq 0.50$ [44]. In order to explore the impacts of the Covid-19 lockdown and relevant pre-defined vulnerabilities on capabilities, mental health/well-being and social support, multivariable linear regression analyses were conducted using the OxCAP-MH, HADS-D, HADS-A, MSPSS and WHO-5 scores as dependent variables and six binary variables that defined vulnerable groups as independent variables. Analyses were adjusted for age, gender, having children, education level and initial employment status.

The potential impact of current depression, anxiety and social support on capabilities was investigated separately in a multivariable regression with OxCAP-MH capability score as the dependent variable and HADS-D, HADS-A, MSPSS scores as independent variables, adjusted for sociodemographic characteristics (age, gender, having children, education level and initial employment status) and the six relevant vulnerabilities as described above. Significance level of $p<0.05$ was considered in all analyses. Analyses were conducted on complete cases in STATA v.15.1 [45].

\section{Results}

\section{Participant characteristics}

Of the 848 persons who accessed the survey, 560 respondents $(74.1 \%$ female, mean age $M=40.22$ years, $S D=11.60)$ completed it and were included in the analyses (Fig. 1). The average time needed to complete the survey was $17 \mathrm{~min}$.

The majority of participants were Austrian citizens (87\%) and employed at the beginning of the Covid-19 lockdown (73\%). More than half of the survey participants $(56 \%)$ had children, $52 \%$ were married or had a registered partnership. Data relating to the sociodemographic characteristics of the sample compared to official Austrian population statistics, with respect to age, gender, distribution of population across federal states [46], migration background [47], education level [48], and employment status [49], are shown in Table 1.

\section{Vulnerabilities}

A total of $13 \%$ of the respondents $(N=72)$ were categorised as belonging to the 'at risk' group based on age and/or co-existing physical health conditions. While $17 \%$ of the participants $(N=97)$ reported that they received treatment for mental disorders before the period of interest, only $6 \%$ of the participants $(N=34)$ reported receiving mental health treatment during the pandemic. Overall, only $30 \%$ of those with a mental health service use history $(N=29)$ reported receiving treatment also during the lockdown.

A total of $1 \%$ of participants $(N=7)$ had been diagnosed with Covid-19, another 6\% $(N=32)$ of the participants experienced Covid-19-like symptoms without being tested, and $20 \%$ of the respondents $(N=110)$ had indirect Covid-19 experience through an infected friend and/or family member, or knew someone who died of Covid-19. Employment status was affected for $15 \%(N=$ 84) of participants (job terminated: $3 \%, N=15$; shortterm work: $12 \%, N=69$ ), and $38 \%$ of the respondents $(N=214)$ reported having a job categorised as 'critical worker' (Table 1). 


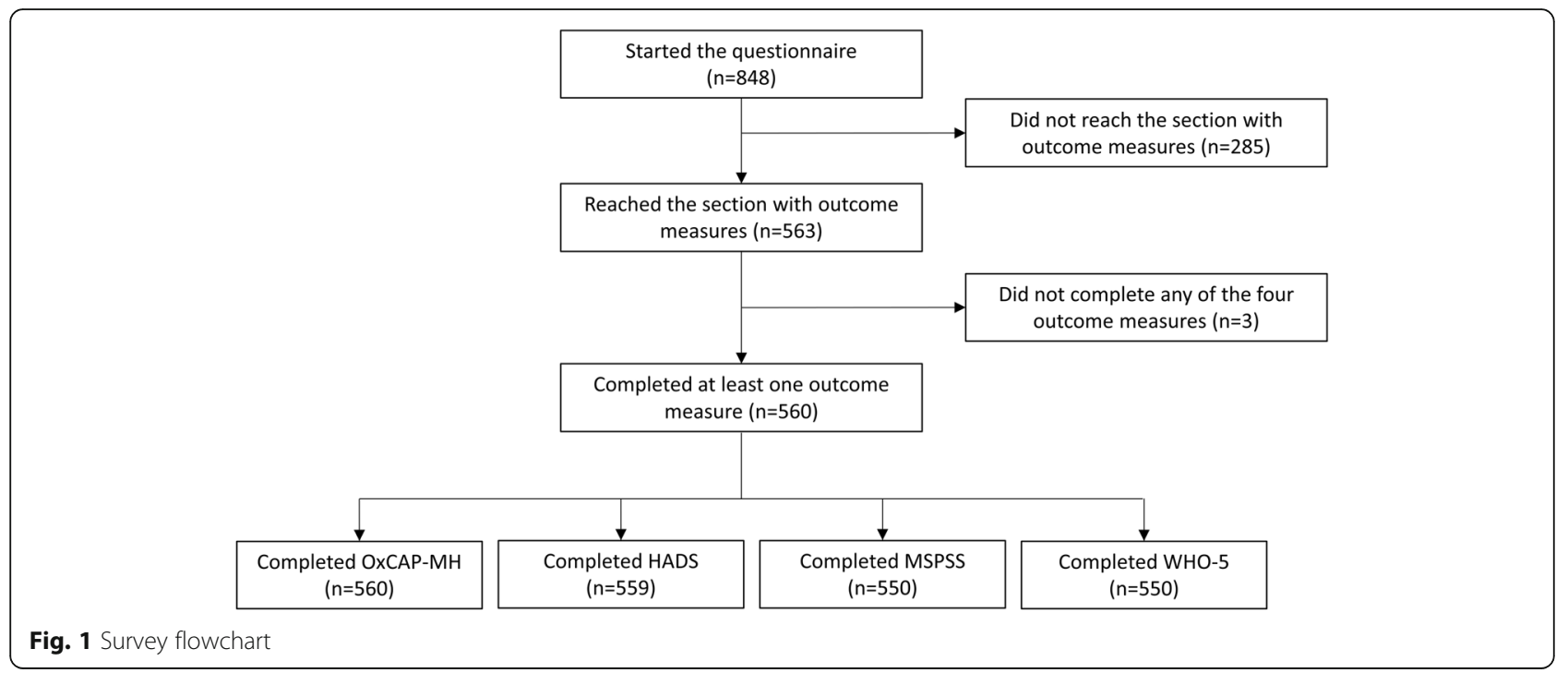

The level of missing values for the standardised outcome instruments was low with a maximum of ten observations missing (1.8\%) for MSPSS and WHO-5. The mean OxCAP-MH score was $74.10(S D=12.30)$. The mean WHO-5 score was $15.10(S D=4.80)$ with $31 \%$ $(N=174)$ of the respondents reporting a score below 13 indicating low mental well-being [42]. The mean scores on HADS-A and HADS-D subscales were $6.26(S D=$ $4.19)$ and $4.72(S D=4.09)$, respectively, indicating that respondents on average reported higher levels of anxiety than depression symptoms. A total of $74 \%$ of participants $(N=416)$ reached the threshold of $>5$ for high social support on the MPSS scale. Average scores for the MSPSS subscales were 5.41 for family support, 5.53 for support from friends and 5.96 for support from significant others.

\section{Correlations between capability well-being, mental health/well-being and social support outcomes}

Capability well-being (OxCAP-MH) was significantly strongly/moderately associated with all other outcome measures, the strongest correlation being with depression (HADS-D: $r(557)=-.64, p<.01 ;$ HADS-A: $r$ $(557)=-.56, p<.01 ; \quad$ WHO-5: $r(448)=.58, \quad p<.01$; MSPSS: $r(448)=.42, p<.01)$. In terms of social support, capabilities and depression had the same strength of correlations, but of opposite directions. (Table 2).

Outcome associations with different types of vulnerability Outcome associations with different types of vulnerabilities adjusted for sociodemographics are shown in Table 3. Past mental health treatment had a significant negative effect across all outcome measures with an associated capability well-being score reduction of -6.54 $(b=-6.54, t(502)=-4.73, p<.01)$, while direct Covid-
19 experience had the second most detrimental impact with an associated capability well-being score reduction of $-4.58(b=-4.58, t(502)=-2.27, p=0.02)$. Capabilities were similarly negatively affected also for those who belonged to the category 'at risk' $(b=-4.45, t$ (502) $=-$ $2.70, p<.01)$. These correspond to capability deprivations of $-9 \%$ and $-6 \%$, respectively, when compared to the average capability level of the study cohort.

Having employment status affected by the pandemic produced consistently lower capability and mental wellbeing scores as well as higher depression and anxiety scores, but these associations did not reach statistical significance. We did not observe any significant impacts for the category 'critical worker' either.

\section{Associations between capability well-being and current depression, anxiety and social support levels}

Additional associations between current levels of depression and anxiety as well as social support with capability well-being were investigated in a separate multivariable regression analysis adjusted for all vulnerabilities and sociodemographics (Table 4). Current levels of depression and anxiety separately showed a capability score reduction of $-1.77(b=-1.77, t(500)=-16.89, p<.01)$ and $-1.50(b=-1.50, t(500)=-13.52, p<.01)$, respectively, per one point difference in the relevant HADS scores. Social support on the other hand proved to be a major capability resilience factor. One point score improvement on the MSPSS scale was associated with an improvement of $+3.75(b=3.75, t(491)=9.60, p<.01)$ in the capability scores.

\section{Discussion}

This is the first study to assess the impact of the Covid19 lockdown and relevant vulnerabilities on capabilities 
Table 1 Characteristics of the survey cohort

\begin{tabular}{|c|c|c|c|}
\hline & \multicolumn{2}{|c|}{$\begin{array}{l}\text { Covid-19 Study } \\
n=560\end{array}$} & \multirow{2}{*}{$\begin{array}{l}\text { Austrian population } \\
\%\end{array}$} \\
\hline & $n$ & $\%$ & \\
\hline \multicolumn{4}{|l|}{ Gender } \\
\hline Female & 416 & $74 \%$ & $51 \%$ \\
\hline Male & 143 & $26 \%$ & $49 \%$ \\
\hline Diverse & 1 & $0 \%$ & \\
\hline Missing & 0 & $0 \%$ & \\
\hline \multicolumn{4}{|l|}{ Age } \\
\hline $18-29$ & 97 & $17 \%$ & $18 \%$ \\
\hline $30-49$ & 319 & $57 \%$ & $34 \%$ \\
\hline $50-64$ & 124 & $22 \%$ & $26 \%$ \\
\hline $65-79$ & 13 & $2 \%$ & $23 \%$ \\
\hline Missing & 7 & $1 \%$ & \\
\hline \multicolumn{4}{|l|}{ Federal state } \\
\hline Burgenland & 12 & $2 \%$ & $3 \%$ \\
\hline Carinthia & 41 & $7 \%$ & $6 \%$ \\
\hline Lower Austria & 109 & $20 \%$ & $19 \%$ \\
\hline Upper Austria & 66 & $12 \%$ & $17 \%$ \\
\hline Salzburg & 25 & $5 \%$ & $6 \%$ \\
\hline Styria & 63 & $11 \%$ & $14 \%$ \\
\hline Tyrol & 24 & $4 \%$ & $9 \%$ \\
\hline Vorarlberg & 5 & $1 \%$ & $4 \%$ \\
\hline Vienna & 215 & $38 \%$ & $21 \%$ \\
\hline Missing & 0 & $0 \%$ & \\
\hline \multicolumn{4}{|l|}{ Migration background } \\
\hline EU-Members before 2004/EWR/Switzerland & 33 & $6 \%$ & $3 \%$ \\
\hline EU-Members joined 2004 and after & 14 & $3 \%$ & $5 \%$ \\
\hline Former Yugoslavia (not-EU), Turkey & 7 & $1 \%$ & $3 \%$ \\
\hline Other countries & 12 & $2 \%$ & $5 \%$ \\
\hline Austrian roots & 489 & $87 \%$ & $84 \%$ \\
\hline Missing & 5 & $1 \%$ & \\
\hline \multicolumn{4}{|l|}{ Education } \\
\hline Primary education & 13 & $2 \%$ & $26 \%$ \\
\hline Vocational school for apprentices & 68 & $12 \%$ & $32 \%$ \\
\hline Intermediate technical and vocational school & 45 & $8 \%$ & $14 \%$ \\
\hline General secondary education and vocational colleges & 132 & $24 \%$ & $15 \%$ \\
\hline Higher education & 302 & $54 \%$ & $13 \%$ \\
\hline Missing & 0 & $0 \%$ & \\
\hline \multicolumn{4}{|l|}{ Employment status } \\
\hline Housekeeping & 28 & $5 \%$ & $2 \%$ \\
\hline Student & 37 & $7 \%$ & $4 \%$ \\
\hline Employed & 410 & $73 \%$ & $64 \%$ \\
\hline Self-employed & 37 & $7 \%$ & $9 \%$ \\
\hline Unemployed & 16 & $3 \%$ & $2 \%$ \\
\hline
\end{tabular}


Table 1 Characteristics of the survey cohort (Continued)

\begin{tabular}{|c|c|c|c|}
\hline & \multicolumn{2}{|c|}{$\begin{array}{l}\text { Covid-19 Study } \\
n=560\end{array}$} & \multirow{2}{*}{$\begin{array}{l}\text { Austrian population } \\
\%\end{array}$} \\
\hline & $\bar{n}$ & $\%$ & \\
\hline Retired & 25 & $4 \%$ & $19 \%$ \\
\hline Missing & 7 & $1 \%$ & \\
\hline \multicolumn{4}{|l|}{ Family status } \\
\hline Single & 204 & $36 \%$ & \\
\hline Married or registered partnership, living together & 266 & $48 \%$ & \\
\hline Married or registered partnership, living separately & 20 & $4 \%$ & \\
\hline Widowed & 6 & $1 \%$ & \\
\hline Divorced & 46 & $8 \%$ & \\
\hline Missing & 18 & $3 \%$ & \\
\hline \multicolumn{4}{|l|}{ Children } \\
\hline Yes & 311 & $56 \%$ & \\
\hline No & 245 & $44 \%$ & \\
\hline Missing & 4 & $1 \%$ & \\
\hline \multicolumn{4}{|l|}{ Categorised as 'at risk' group ${ }^{a}$} \\
\hline Yes & 72 & $13 \%$ & \\
\hline No & 486 & $87 \%$ & \\
\hline Missing & 2 & $0 \%$ & \\
\hline \multicolumn{4}{|l|}{ Received mental health treatment before the pandemic } \\
\hline Yes & 97 & $17 \%$ & \\
\hline No & 456 & $81 \%$ & \\
\hline Missing & 7 & $1 \%$ & \\
\hline \multicolumn{4}{|c|}{ Received mental health treatment during the pandemic lockdown } \\
\hline Yes & 34 & $6 \%$ & \\
\hline No & 518 & $93 \%$ & \\
\hline Missing & 7 & $1 \%$ & \\
\hline Direct Covid-19 experience & 39 & $7 \%$ & \\
\hline Tested positive for Covid-19 & 7 & $1 \%$ & \\
\hline Experienced symptoms of Covid-19, not tested & 32 & $6 \%$ & \\
\hline Missing & 0 & $0 \%$ & \\
\hline Indirect Covid-19 experience ${ }^{\text {b }}$ & 110 & $20 \%$ & \\
\hline Close friend tested positive for Covid-19 & 46 & $9 \%$ & \\
\hline Family member tested positive for Covid-19 & 32 & $6 \%$ & \\
\hline Knew someone who died of Covid-19 & 44 & $8 \%$ & \\
\hline Missing & 0 & $0 \%$ & \\
\hline Employment status affected by Covid-19 & 84 & $15 \%$ & \\
\hline Fired from job & 15 & $3 \%$ & \\
\hline Short-time working & 69 & $12 \%$ & \\
\hline Missing & 6 & $1 \%$ & \\
\hline \multicolumn{4}{|l|}{ Critical worker } \\
\hline Yes & 214 & $38 \%$ & \\
\hline No & 330 & $59 \%$ & \\
\hline Missing & 16 & $3 \%$ & \\
\hline
\end{tabular}


Table 1 Characteristics of the survey cohort (Continued)

\begin{tabular}{|c|c|c|c|}
\hline & \multicolumn{2}{|c|}{$\begin{array}{l}\text { Covid-19 Study } \\
n=560\end{array}$} & \multirow{2}{*}{$\begin{array}{l}\text { Austrian population } \\
\%\end{array}$} \\
\hline & $n$ & $\%$ & \\
\hline OxCAP-MH score (mean, SD) & 74.10 & 12.30 & \\
\hline Missing & 0 & $0 \%$ & \\
\hline HADS-D (mean, SD) & 4.72 & 4.09 & \\
\hline HADS depression score normal $(0-7)$ & 436 & $78 \%$ & \\
\hline HADS depression score borderline (8-10) & 62 & $11 \%$ & \\
\hline HADS depression score abnormal (11-21) & 61 & $11 \%$ & \\
\hline Missing & 1 & $0 \%$ & \\
\hline HADS-A (mean, SD) & 6.26 & 4.19 & \\
\hline HADS anxiety score normal (0-7) & 362 & $65 \%$ & \\
\hline HADS anxiety score borderline (8-10) & 108 & $19 \%$ & \\
\hline HADS anxiety score abnormal (11-21) & 89 & $16 \%$ & \\
\hline Missing & 1 & $0 \%$ & \\
\hline MSPSS score (mean, SD) & 5.64 & 1.23 & \\
\hline MSPSS high support (5.1-7) & 416 & $74 \%$ & \\
\hline MSPSS moderate support (3-5) & 112 & $20 \%$ & \\
\hline MSPSS low support (0-2.99) & 22 & $4 \%$ & \\
\hline Missing & 10 & $2 \%$ & \\
\hline WHO-5 score (mean, SD) & 15.10 & 4.80 & \\
\hline Missing & 10 & $2 \%$ & \\
\hline
\end{tabular}

${ }^{a}$ Participants were categorised as 'at risk' group if they were aged 65 or more, and/or they self-reported at least one of the listed diseases: heart/cardiovascular disease, stroke/cerebrovascular disease, lung disease (e.g. asthma, cystic fibrosis, COPD), liver disease (e.g. hepatitis), cancer;

${ }^{b}$ Respondents included in "direct Covid-19 experience" variable were excluded from this group

well-being, mental health and social support and their associations as observed in Austria.

Our findings that Covid-19 direct experience is associated with intensified anxiety symptoms, lower mental well-being and lower capabilities are in line with other recent studies exploring the impact of the Covid-19 pandemic on mental health and well-being in Austria [28, $29,50-52]$. Our study showed that participants who reported mental health treatment before the Covid-19

Table 2 Correlations between capability well-being, mental health/well-being and social support outcomes

\begin{tabular}{llllll}
\hline & OxCAP-MH & HADS-D & HADS-A & MSPSS & WHO-5 \\
\hline OxCAP-MH & 1 & & & & \\
HADS-D & $-0.64^{* * *}$ & 1 & & & \\
HADS-A & $-0.56^{* * *}$ & $0.75^{* * *}$ & 1 & & \\
MSPSS & $0.42^{* * *}$ & $-0.42^{* * *}$ & $-0.30^{* * *}$ & 1 & \\
WHO-5 & $0.58^{* * *}$ & $-0.70^{* * *}$ & $-0.67^{* * *}$ & $0.34^{* * *}$ & 1 \\
\hline
\end{tabular}

Note: ${ }^{*} p<0.05,{ }^{* *} p<0.01,{ }^{* * *} p<0.001 ;$ OxCAP-MH Oxford CAPabilities questionnaire-Mental Health; HADS-D Hospital Anxiety and Depression ScaleDepression subscale, HADS-A Hospital Anxiety and Depression Scale-Anxiety subscale, MSPSS Multidimensional Scale of Perceived Social Support, WHO-5 World Health Organisation-Five Well-being Index pandemic reported worse outcomes on all measures, including the OxCAP-MH, HADS-D, HADS-A, MSPSS and WHO-5. However, only the OxCAP-MH capability questionnaire showed a significant negative impact for participants categorised as belonging to the 'at risk' group. It should be noted that it is likely that the Covid19 lockdown restrictions accentuated levels of distress experienced by those with existing physical health conditions. This association has not been captured by any other outcome measure, suggesting an increased sensitivity of the OxCAP-MH in comparison to the other scales used in this study and confirming the advantage of its broader measurement scope when assessing the well-being impact of a pandemic and related public health measures. The study also confirmed that the capability approach, which provides an indication of people's freedom to engage in forms of being and doing that are of intrinsic value to the person, has direct relevance to situations/policies that inherently limit personal freedoms, i.e. public health emergencies.

The vulnerabilities referred to in this study as 'employment status affected' by Covid-19 or being a 'critical worker' were not significantly associated with any of the outcomes. Besides the issue of sample size, this may also 
Table 3 Associations between capability well-being, depression, anxiety, social support, mental well-being and different types of vulnerabilities

\begin{tabular}{|c|c|c|c|c|c|c|c|c|c|c|}
\hline \multirow[t]{2}{*}{ Vulnerabilities } & \multicolumn{2}{|c|}{ OxCAP-MH score } & \multicolumn{2}{|c|}{ HADS-D score } & \multicolumn{2}{|c|}{ HADS-A score } & \multicolumn{2}{|l|}{ MSPSS score } & \multicolumn{2}{|c|}{ WHO-5 score } \\
\hline & $\beta(S E)$ & $95 \% \mathrm{Cl}$ & $\beta(S E)$ & $95 \% \mathrm{Cl}$ & $B(S E)$ & $95 \% \mathrm{Cl}$ & $B(S E)$ & $95 \% \mathrm{Cl}$ & $\beta(S E)$ & $95 \% \mathrm{Cl}$ \\
\hline At risk group & $\begin{array}{l}-4.45^{* *} \\
(1.65)\end{array}$ & $\begin{array}{l}-7.68,- \\
1.21\end{array}$ & $0.29(0.56)$ & $\begin{array}{l}-0.80 \\
1.40\end{array}$ & $0.82(0.57)$ & $\begin{array}{l}-0.30 \\
1.93\end{array}$ & $0.03(0.17)$ & $\begin{array}{l}-0.31 \\
0.38\end{array}$ & $\begin{array}{l}-0.80 \\
(0.66)\end{array}$ & $\begin{array}{l}-2.09 \\
0.50\end{array}$ \\
\hline $\begin{array}{l}\text { Past mental health } \\
\text { treatment }\end{array}$ & $\begin{array}{l}-6.54^{* * *} \\
(1.38)\end{array}$ & $\begin{array}{l}-9.26,- \\
3.82\end{array}$ & $\begin{array}{l}1.97^{* * *} \\
(0.47)\end{array}$ & $\begin{array}{l}1.05 \\
2.90\end{array}$ & $\begin{array}{l}2.09^{* * *} \\
(0.48)\end{array}$ & $\begin{array}{l}1.16 \\
3.03\end{array}$ & $\begin{array}{l}-0.44^{* *} \\
(0.15)\end{array}$ & $\begin{array}{l}-0.74,- \\
0.15\end{array}$ & $\begin{array}{l}-1.61^{* *} \\
(0.56)\end{array}$ & $\begin{array}{l}-2.71,- \\
0.50\end{array}$ \\
\hline $\begin{array}{l}\text { Direct Covid-19 } \\
\text { experience }\end{array}$ & $\begin{array}{l}-4.58^{*} \\
(2.01)\end{array}$ & $\begin{array}{l}-8.54,- \\
0.62\end{array}$ & $1.23(0.69)$ & $\begin{array}{l}-0.12 \\
2.58\end{array}$ & $\begin{array}{l}1.77^{*} \\
(0.69)\end{array}$ & $\begin{array}{l}0.40 \\
3.13\end{array}$ & $-0.09(0.22)$ & $\begin{array}{l}-0.49 \\
0.35\end{array}$ & $\begin{array}{l}-1.59^{*} \\
(0.82)\end{array}$ & $\begin{array}{l}-3.20 \\
0.00\end{array}$ \\
\hline $\begin{array}{l}\text { Indirect Covid-19 } \\
\text { experience }\end{array}$ & $-0.11(1.29)$ & $\begin{array}{l}-2.65 \\
2.43\end{array}$ & $0.25(0.44)$ & $\begin{array}{l}-0.61 \\
1.12\end{array}$ & $\begin{array}{l}0.97^{*} \\
(0.45)\end{array}$ & $\begin{array}{l}0.09 \\
1.85\end{array}$ & $\begin{array}{l}-0.31^{*} \\
(0.14)\end{array}$ & $\begin{array}{l}-0.59,- \\
0.04\end{array}$ & $0.04(0.53)$ & $\begin{array}{l}-0.99 \\
1.08\end{array}$ \\
\hline $\begin{array}{l}\text { Employment status } \\
\text { affected }\end{array}$ & $-2.31(1.55)$ & $\begin{array}{l}-5.36 \\
0.74\end{array}$ & $0.80(0.53)$ & $\begin{array}{l}-0.24 \\
1.84\end{array}$ & $0.81(0.53)$ & $\begin{array}{l}-0.24 \\
1.90\end{array}$ & $0.01(0.16)$ & $\begin{array}{l}-0.33 \\
0.31\end{array}$ & $-1.20(0.62)$ & $\begin{array}{l}-2.43 \\
0.03\end{array}$ \\
\hline Critical worker & $0.08(1.12)$ & $\begin{array}{l}-2.13 \\
2.30\end{array}$ & $-0.33(0.38)$ & $\begin{array}{l}-1.08 \\
0.43\end{array}$ & $-0.32(0.39)$ & $\begin{array}{l}-1.09 \\
0.44\end{array}$ & $\begin{array}{l}-0.07 \\
(0.12)\end{array}$ & $\begin{array}{l}-0.30 \\
0.17\end{array}$ & $\begin{array}{l}-0.49 \\
(0.45)\end{array}$ & $\begin{array}{l}-1.38 \\
0.40\end{array}$ \\
\hline Constant & $\begin{array}{l}68.90^{* * *} \\
(4.83)\end{array}$ & $\begin{array}{l}59.41 \\
78.38\end{array}$ & $3.08(1.65)$ & $\begin{array}{l}-1.15 \\
6.32\end{array}$ & $\begin{array}{l}6.44^{* * *} \\
(1.66)\end{array}$ & $\begin{array}{l}3.17 \\
9.71\end{array}$ & $\begin{array}{l}6.11^{* * *} \\
(0.51)\end{array}$ & $5.11,7.12$ & $\begin{array}{l}16.35^{* * *} \\
(1.93)\end{array}$ & $\begin{array}{l}12.55 \\
20.15\end{array}$ \\
\hline
\end{tabular}

Note: Standard errors (SE) in parentheses ${ }^{*} p<0.05,{ }^{* *} p<0.01,{ }^{* * *} p<0.001$; Statistically significant coefficients $(p<0.05)$ in bold; Analyses adjusted for age, gender, migration status, education level, having children, employment status; OxCAP-MH Oxford CAPabilities questionnaire-Mental Health, HADS-D Hospital Anxiety and Depression Scale-Depression subscale, HADS-A Hospital Anxiety and Depression Scale-Anxiety subscale, MSPSS Multidimensional Scale of Perceived Social Support, WHO-5 World Health Organisation-Five Well-being Index

reflect the Austrian government's employment support policy implemented in the early stages of the pandemic including the introduction of the short-term working scheme to help retain jobs $[53,54]$.

When considering the average capability well-being score observed in our cohort, the relative impact of different vulnerabilities and other factors on capability levels were estimated between $-9 \%$ for those reporting past mental health treatment vs. $+5 \%$ for reporting one score higher on the social support scale. In future analyses, the outcome scores obtained in this study could also be compared to scores observed in studies prior to the Covid-19 pandemic to further asses the overall impact of this public health emergency and lockdown on the well-being of the Austrian population. Previous studies using the WHO-5 instrument found that $26-27 \%$ of the Austrian sample reported scores corresponding to

Table 4 Associations between capability well-being and current depression (HADS-D), anxiety (HADS-A) and social support (MSPSS) levels

\begin{tabular}{lll}
\hline & OxCAP-MH & \\
\cline { 2 - 3 } & $\mathbf{B}(\mathbf{S E})$ & $\mathbf{9 5 \%} \mathbf{C l}$ \\
\hline HADS-D & $-1.77(0.10)^{* * *}$ & $-1.97,-1.56$ \\
HADS-A & $-1.50(0.11)^{* * *}$ & $-1.72,-1.28$ \\
MSPSS & $3.75(0.39)^{* * *}$ & $2.98,4.51$ \\
\hline
\end{tabular}

Note: ${ }^{*} p<0.05,{ }^{* *} p<0.01,{ }^{* * *} p<0.001$; Analyses adjusted for age, gender, migration status, education level, having children, employment status, at risk group for Covid-19, past mental health treatment, direct Covid-19 experience, indirect Covid-19 experience, employment status affected by Covid-19, critical worker; OxCAP-MH Oxford CAPabilities questionnaire-Mental Health, HADS-D Hospital Anxiety and Depression Scale-Depression subscale, HADS-A Hospital Anxiety and Depression Scale-Anxiety subscale, MSPSS Multidimensional Scale of Perceived Social Support, WHO-5 World Health Organisation-Five Well-being Index low mental well-being $[55,56]$. This is lower than the $31 \%$ of respondents who were identified as having low mental well-being (WHO-5 score below 13) in our study. Furthermore, $19 \%$ of the participants in this study had borderline and 16\% 'abnormal' anxiety levels according to HADS-A scoring system, somewhat higher than the levels reported in earlier Austrian studies [57-60]. These results seem to be confirmative of the expected negative impacts of the Covid-19 pandemic, including those of the lockdown, on mental well-being including increased levels of anxiety and stress. Previous studies using the MSPSS scale in Austrian populations reported comparable scores, indicating relatively high social support $[61,62]$.

In addition to providing an indication of the Covid-19 and lockdown impacts on vulnerable groups, this study also highlighted the interactions between capability wellbeing levels and current mental health that indicate a strong negative impact of current depression and anxiety. On the other hand, social support was shown as a major capability resilience factor. Future (public health) policies should take the strong associations between capabilities and current mental health and social support levels directly into consideration to minimise the negative long-term health, social and economic issues related to future public health emergencies.

Furthermore, our results suggest that amongst all investigated vulnerabilities, people with past mental health treatment represent the most vulnerable group. A recent study from Austria found that the number of people treated with psychotherapy during lockdown (personal, phone or virtual contacts) decreased by one-third [63]. In our study, the proportion of people receiving mental 
health treatment during lockdown in comparison to the period before the pandemic was $6 \%$ vs. $17 \%$, respectively. We found evidence of the continuation of treatment between the two periods for only $30 \%$ of those participants who received mental health treatment prior to the pandemic. Even under the most conservative assumptions, these results suggest a substantial level of underutilisation of mental health services (due to whatever causes) during the lockdown period. For future strategic healthcare planning during next waves of the pandemic, policy makers and health and social care providers need to be aware of the exceptional vulnerability of this group and efforts should be focused on maintaining continuity in mental health service provision. Digital e-health treatment options provide potential solution to assure this continuity of treatment whilst simultaneously protecting the health of the service-users and professionals [64, 65].

The results of this research also have major implications for government departments, social care services and community-based support initiatives in planning how best to support the population during future pandemics, and in terms of the special attention needed for those with pre-existing mental health service use. Findings also provide crucial evidence for policy makers and members of the public by indicating how important and protective social support networks can be in mitigating the mental health and (capability) well-being impacts of public health emergencies through increased resilience. The latter finding goes beyond the health sector with relevant implications also for the education sector when considering decisions about university openings and necessary support networks for students. Future research should explore whether the observed impacts on capabilities, mental health and social support levels remain, worsen or diminish (via adjustment) as the pandemic continues and how they develop in the long-term after the public health situation is resolved.

Furthermore, strategies that can help to alleviate the negative impacts of the Covid-19 lockdown in the Austrian population should be identified. Priority should be given to assuring the continuity of mental health services, as well as identifying new cases of mental disorders, mental distress and anxiety that might arise due to lockdowns. This will require the capacity of mental health support services to be increased, policy initiatives to be communicated in a clear and transparent way so that anxiety is reduced among the population, and the introduction of work arrangements that allow for homeschooling for both parents (reducing the burden posed on mothers) that prevent loss of household income [66]. Moreover, governments should implement economic measures and reinforce essential health, social and education services to identify population needs, reduce inequalities in health and protect most vulnerable citizens including people with pre-existing conditions, elderly, migrant population, children and those with lower socio-economic status [67].

The main limitation of our study is that the participants completed the survey retrospectively about 1 month after the lockdown (mid-May 2020). This timelag may have introduced some recall bias considering the self-reported outcome measures. Since data were collected at the time when the number of new Covid-19 cases were relatively low and the Austrian epidemic curve has flattened, we assume that the presented estimates are more conservative and optimistic than if the survey questions would have been completed directly during the lockdown. Moreover, since the analysis is based on one measurement point, the study allows no causal conclusions. Our study is also prone to limitations of online survey; results are based fully on selfreporting with the potential to reporting bias [68] and some groups (females, younger ages, higher educated), were over-represented in the survey sample compared to the general population $[69,70]$. The survey on the other hand achieved satisfactory representation in terms of more than half of the Austrian provinces, migration background and employment status.

\section{Conclusions}

This research contributes to the understanding of the impact that pandemics and nationwide responses to pandemics can have on mental health and broader capability well-beings in light of their major policy relevance. Furthermore, the study confirms that the OxCAP-MH capability measure is a valid and relevant tool to understand the impacts of the Covid-19 pandemic and related public health measures, which due to the negative externalities of any infectious disease inherently limit individual freedoms to some extent. Future research is planned to compare cultural aspects of lockdown experiences across countries and explore longterm mental health/well-being impacts from the perspective of the capability approach.

\section{Supplementary Information}

The online version contains supplementary material available at https://doi. org/10.1186/s12889-021-10351-5.

\section{Additional file 1.}

\section{Abbreviations}

HADS: The Hospital Anxiety and Depression Scale; MSPSS: The

Multidimensional Scale of Perceived Social Support; OxCAP-MH: The Oxford CAPabilities questionnaire-Mental Health; WHO: World Health Organisation; WHO-5: The World Health Organisation-Five Well-being Index

\section{Acknowledgements}

We would like to say thank you to all survey participants and to colleagues at the Department of Health Economics for piloting the survey. 


\section{Authors' contributions}

JS, RW and CV conceived the study idea, and developed the conceptual framework and methods of the research. JS provided the resources to this study. TH and AL executed the survey and conducted the analysis supervised by JS. JS, TH and AL wrote the manuscript which was reviewed by all. All authors provided critical feedback and helped shape the research analysis and manuscript. All authors approved the final manuscript.

\section{Funding}

The study received no funding.

\section{Availability of data and materials}

The datasets generated during the current study and the study protocol have been released in a scientific data repository and can be accessed under the link: https://doi.org/10.5281/zenodo.4271534.

\section{Ethics approval and consent to participate}

The study and experimental protocols were approved by the Ethics Committee of the Medical University of Vienna on 26 May 2020 (EK Nr: 1529/ 2020). Informed consent was obtained from all individual participants included in the study. All procedures performed in studies involving human participants were in accordance with the ethical standards of the Ethics Commission of the Medical University of Vienna (EK 1529/2020) and with the 1964 Helsinki declaration and its later amendments or comparable ethical standards.

\section{Consent for publication}

Not applicable.

\section{Competing interests}

JS has led the development of the OxCAP-MH measure. The remaining authors declare that they have no conflict of interest.

\section{Author details}

${ }^{1}$ Department of Health Economics, Center for Public Health, Medical University of Vienna, Kinderspitalgasse 15, 1090 Vienna, Austria. ${ }^{2}$ Department of Psychiatry, University of Oxford, Warneford Hospital, Oxford OX3 7JX, UK. ${ }^{3}$ Primary Care and Mental Health, Institute of Population Health, University of Liverpool, School of Psychology, Brownlow Hill, Liverpool L69 3GB, UK.

\section{Received: 9 November 2020 Accepted: 11 January 2021}

\section{Published online: 08 February 2021}

\section{References}

1. WHO. WHO Coronavirus Disease (COVID-19) Dashboard. https://covid19. who.int/. Accessed 30 Oct 2020.

2. UNDP. COVID-19 and human development: Assessing the crisis, envisioning the recovery. http://hdr.undp.org/en/hdp-covid. Accessed 30 Oct 2020.

3. Shah K, Kamrai D, Mekala H, Mann B, Desai K, Patel RS. Focus on mental health during the coronavirus (COVID-19) pandemic: applying Learnings from the past outbreaks. Cureus. 2020;12(3):e7405. https://doi.org/10.7759/ cureus.7405.

4. Caqueo-Urízar A, Urzúa A, Aragón-Caqueo D, Charles CH, El-Khatib Z, Otu A, et al. Mental health and the COVID-19 pandemic in Chile. Psychol Trauma. 2020;12(5):521-3. https://doi.org/10.1037/tra0000753.

5. Chen S, Bonanno GA. Psychological adjustment during the global outbreak of COVID-19: a resilience perspective. Psychol Trauma. 2020;12(S1):S51-S4. https://doi.org/10.1037/tra0000685.

6. Cullen W, Gulati G, Kelly BD. Mental health in the COVID-19 pandemic. QJM. 2020;113(5):311-2. https://doi.org/10.1093/qjmed/hcaa110.

7. Dong L, Bouey J. Public mental health crisis during COVID-19 pandemic, China. Emerg Infect Dis. 2020;26(7):1616-8. https://doi.org/10.3201/eid2607. 200407.

8. Javed B, Sarwer A, Soto EB, Mashwani ZU. The coronavirus (COVID-19) pandemic's impact on mental health. Int J Health Plann Manag. 2020;35: 993-6. https://doi.org/10.1002/hpm.3008.

9. Kavčič T, Avsec A, Zager KG. Psychological functioning of Slovene adults during the COVID-19 pandemic: does resilience matter? Psychiatr Q. 2020:110. https://doi.org/10.1007/s11126-020-09789-4.
10. Khoury B, El-Khoury J, Ammar J. Psychological needs and response during the COVID-19 pandemic in Lebanon. Psychol Trauma. 2020;12(5):497-8. https://doi.org/10.1037/tra0000757.

11. Koushik NS. A population mental health perspective on the impact of COVID-19. Psychol Trauma. 2020;12(5):529-30. https://doi.org/10.1037/ tra0000737.

12. Lai J, Ma S, Wang Y, Cai Z, Hu J, Wei N, et al. Factors associated with mental health outcomes among health care workers exposed to coronavirus disease 2019. JAMA Netw Open. 2020;3(3):e203976. https://doi.org/10.1001/ jamanetworkopen.2020.3976.

13. Loades ME, Chatburn E, Higson-Sweeney N, Reynolds S, Shafran R, Brigden A, et al. Rapid Systematic Review: The Impact of Social Isolation and Loneliness on the Mental Health of Children and Adolescents in the Context of COVID-19. J Am Acad Child Adolesc Psychiatry. 2020;59(11): 1218-1239.e3. https://doi.org/10.1016/j.jaac.2020.05.009.

14. Mancini AD. Heterogeneous mental health consequences of COVID-19: costs and benefits. Psychol Trauma. 2020;12(S1):S15-S6. https://doi.org/10. 1037/tra0000894.

15. Pfefferbaum B, North CS. Mental health and the Covid-19 pandemic. N Engl J Med. 2020;383(6):510-2. https://doi.org/10.1056/NEJMp2008017.

16. Rossi R, Socci V, Talevi D, Mensi S, Niolu C, Pacitti F, et al. COVID-19 pandemic and lockdown measures impact on mental health among the general population in Italy. Front Psychiatry. 2020;11:790. https://doi.org/10. 3389/fpsyt.2020.00790.

17. Seghi F, Barbini B, Franchini L, Colombo C. The challenge of mental health during Covid-19 outbreak: experience from metropolitan area of Milan. Eur Arch Psychiatry Clin Neurosci. 2020:1-2. https://doi.org/10.1007/s00406-02001154-7.

18. Serafini G, Parmigiani B, Amerio A, Aguglia A, Sher L, Amore M. The psychological impact of COVID-19 on the mental health in the general population. QJM. 2020;113(8):531-7. https://doi.org/10.1093/qjmed/hcaa201.

19. Sher $L$. The impact of the COVID-19 pandemic on suicide rates. QJM. 2020; 133(11):707-12. https://doi.org/10.1093/qjmed/hcaa202.

20. Talevi D, Socci V, Carai M, Carnaghi G, Faleri S, Trebbi E, et al. Mental health outcomes of the CoViD-19 pandemic. Riv Psichiatr. 2020;55(3):137-44. https://doi.org/10.1708/3382.33569.

21. Tang F, Liang J, Zhang H, Kelifa MM, He Q, Wang P. COVID-19 related depression and anxiety among quarantined respondents. Psychol Health. 2020:1-15. https://doi.org/10.1080/08870446.2020.1782410.

22. Torales J, O'Higgins M, Castaldelli-Maia JM, Ventriglio A. The outbreak of COVID-19 coronavirus and its impact on global mental health. Int J Soc Psychiatry. 2020;66(4):317-20. https://doi.org/10.1177/0020764020915212.

23. Sen A. Commodities and capabilities: OUP catalogue; 1999.

24. Sen A. Capability and well-being. In: Nusbaum M, Sen A, editors. The Quality of Life: Oxford: Clarendon Press; 1993. p. 30-53.

25. Anand P, Ferrer B, Gao Q, Nogales R, Unterhalter E. COVID-19 as a capability crisis: using the capability framework to understand policy challenges. J Human Dev Capabil. 2020:293-9. https://doi.org/10.1080/19452829.2020. 1789079.

26. Gibney E. Whose coronavirus strategy worked best? Scientists hunt most effective policies. Nature. 2020;581(7806):15-6. https://doi.org/10.1038/ d41586-020-01248-1.

27. Moshammer H, Poteser M, Lemmerer $K$, Wallner $\mathrm{P}$, Hutter HP. Time course of COVID-19 cases in Austria. Int J Environ Res Public Health. 2020;17(9): 3270. https://doi.org/10.3390/ijerph17093270.

28. Pieh C, Budimir S, Probst T. Mental health during COVID-19 lockdown: a comparison of Austria and the UK. SSRN. https://doi.org/10.2139/ssrn.3592372.

29. Traunmüller C, Stefitz R, Gaisbachgrabner K, Schwerdtfeger A. Psychological correlates of COVID-19 pandemic in the Austrian population. BMC Public Health. 2020;20:1395. https://doi.org/10.1186/s12889-020-09489-5.

30. Brunner R. Why do people with mental distress have poor social outcomes? Four lessons from the capabilities approach. Soc Sci Med. 2017;191:160-7.

31. Mitchell PM, Al-Janabi H, Byford S, Kuyken W, Richardson J, lezzi A, et al. Assessing the validity of the ICECAP-A capability measure for adults with depression. BMC Psychiatry. 2017;17(1):46. https://doi.org/10.1186/s12888017-1211-8.

32. Hackert MQN, van Exel J, Brouwer WBF. Does the ICECAP-O cover the physical, mental and social functioning of older people in the UK? Qual Life Res. 2019;28(3):761-70. https://doi.org/10.1007/s11136-018-2042-x.

33. Łaszewska A, Schwab M, Leutner E, Oberrauter M, Spiel G, Simon J. Measuring broader wellbeing in mental health services: validity of the 
German language OxCAP-MH capability instrument. Qual Life Res. 2019; 28(8):2311-23. https://doi.org/10.1007/s11136-019-02187-9.

34. Vergunst F, Jenkinson C, Burns T, Anand P, Gray A, Rugkåsa J, et al. Psychometric validation of a multi-dimensional capability instrument for outcome measurement in mental health research (OxCAP-MH). Health Qual Life Outcomes. 2017;15(1):250. https://doi.org/10.1186/s12955-017-0825-3.

35. Leiner DJ. SoSci Survey (Version 3.1.06). 2019. https://www.soscisurvey.de.

36. White RG, Van Der Boor C. Impact of the COVID-19 pandemic and initial. period of lockdown on the mental health and well-being of adults in the UK. B J Psych Open. 2020;6(5):e90. https://doi.org/10.1192/bjo.2020.79.

37. Simon J, Anand P, Gray A, Rugkåsa J, Yeeles K, Burns T. Operationalising the capability approach for outcome measurement in mental health research. Soc Sci Med. 2013;98:187-96. https://doi.org/10.1016/j.socscimed.2013.09. 019.

38. Simon J, Łaszewska A, Leutner E, Spiel G, Churchman D, Mayer S. Cultural and linguistic transferability of the multi-dimensional OxCAP-MH capability instrument for outcome measurement in mental health: the German language version. BMC Psychiatry. 2018;18(1):173. https://doi.org/10.1186/ s12888-018-1762-3.

39. Snaith RP, Zigmond AS. The hospital anxiety and depression scale. Br Med J. 1986;292(6516):344. https://doi.org/10.1136/bmj.292.6516.344.

40. Bjelland I, Dahl AA, Haug TT, Neckelmann D. The validity of the hospital anxiety and depression scale. An updated literature review. J Psychosom Res. 2002;52(2):69-77. https://doi.org/10.1016/s0022-3999(01)00296-3.

41. Zimet GD, Dahlem NW, Zimet SG, Farley GK. The multidimensional scale of perceived social support. J Pers Assess. 1988;52(1):30-41. https://doi.org/10. 1207/s15327752jpa5201_2.

42. WHO. Wellbeing Measures in Primary Health Care/The Depcare Project. Copenhagen: Report on a WHO Meeting; 1998. https://www.euro.who. int/_data/assets/pdf_file/0016/130750/E60246.pdf Accessed 30 Oct 2020

43. Topp CW, Østergaard SD, Søndergaard S, Bech P. The WHO-5 well-being index: a systematic review of the literature. Psychother Psychosom. 2015; 84(3):167-76. https://doi.org/10.1159/000376585.

44. Cohen J. Statistical power analysis for the behavioral sciences. Hillsdale: Erbaum Press; 1988.

45. StataCorp. Stata Statistical Software: Release 15. College Station: TX: StataCorp LLC; 2017.

46. Statistik Austria. Bevölkerung am 1.1.2019 nach Alter und Bundesland. 2019. http://www.statistik.at/web_de/statistiken/menschen_und_gesellschaft/ bevoelkerung/bevoelkerungsstruktur/bevoelkerung_nach_alter_geschlecht/ 023470.html. Accessed 30 Oct 2020.

47. Statistik Austria. Bevölkerung 2017 nach detaillierter Staatsangehörigkeit, Geschlecht und Bundesland. 2017. http://www.statistik.at/web_de/ statistiken/menschen_und_gesellschaft/bevoelkerung/volkszaehlungen_ registerzaehlungen_abgestimmte_erwerbsstatistik/bevoelkerung_nach_ demographischen_merkmalen/index.html. Accessed 30 Oct 2020.

48. Statistik Austria. Bildungsstand der Bevölkerung ab 15 Jahren 2017 nach Altersgruppen und Geschlecht. 2017. http://www.statistik.at/web_de/ statistiken/menschen_und_gesellschaft/bildung/bildungsstand_der_ bevoelkerung/121189.html. Accessed 30 Oct 2020.

49. Statistik Austria. Austria: Data. Figures Facts http://www.statistik.at/wcm/idc/ idcplg?ldcService=GET_NATIVE_FILE\&dDocName=029252. Accessed 30 Oct 2020.

50. Braun M, Niederkronenthaler T, Till B. SARS CoV-2: Mental Health in Österreich Ausgewählte Ergebnisse zur ersten Befragungswelle, 23.04-05.05. 2020: Unit Suizidforschung und Mental Health Promotion, Abteilung für Sozial- und Präventivmedizin, Zentrum für Public Health, Medizinische Universität Wien; 2020.

51. Nitschke JP, Forbes P, Ali N, Cutler J, Apps MAJ, Lockwood P, Lamm C. Resilience during uncertainty? Greater social connectedness during COVID19 lockdown is associated with reduced distress and fatigue. $\mathrm{Br} J$ Health Psychol. 2020. https://doi.org/10.1111/bjhp.12485.

52. Stieger S, Lewetz D, Swami V. Psychological well-being under conditions of lockdown: an experience sampling study in Austria during the COVID-19 pandemic. PsyArXiv Preprints. 2020. https://doi.org/10.31234/osf.io/qjhfp.

53. Hofer $\mathrm{H}$, Titelbach $\mathrm{G}$, Fink M. Die österreichische Arbeitsmarktpolitik vor dem Hintergrund der Covid-19-Krise. Vienna: Institute for Advanced Studies; 2020. https://irihs.ihs.ac.at/id/eprint/5388/7/ihs-report-2020-hofer-titelbachfink-oesterreich-arbeitsmarktpolitik-covid-19.pdf. Accessed 30 Oct 2020
54. Müller M. The start of the Austrian response to the COVID-19 crisis: a personal account. Wien Klin Wochenschr. 2020;132(13-14):353-5. https://doi. org/10.1007/s00508-020-01693-y.

55. de Wit L, Jelsma JG, van Poppel MN, Bogaerts A, Simmons D, Desoye G, et al. Physical activity, depressed mood and pregnancy worries in European obese pregnant women: results from the DALI study. BMC Pregnancy Childbirth. 2015;15:158.

56. Loder AKF, Schwerdtfeger AR, van Poppel MNM. Perceived greenness at home and at university are independently associated with mental health. BMC Public Health. 2020;20(1):802. https://doi.org/10.1186/s12889-020-84127.

57. Cenik F, Keilani M, Hasenöhrl T, Huber D, Stuhlpfarrer B, Pataraia A, et al. Relevant parameters for recommendations of physical activity in patients suffering from multiple myeloma: a pilot study. Wien Klin Wochenschr. 2020:132:124-31. https://doi.org/10.1007/s00508-019-01582-z.

58. Clever K, Schepper F, Pletschko T, Herschbach P, Christiansen H, Martini J. Psychometric properties of the fear of progression questionnaire for parents of children with cancer (FoP-Q-SF/PR). J Psychosom Res. 2018;107:7-13. https://doi.org/10.1016/j.jpsychores.2018.01.008.

59. Herrmann C, Snaith RP BU. Hospital anxiety and depression scale-deutsche version (HADS-D). Verlag Hans Huber: Ein Fragebogen zur Erfassung von Angst und Depressivität; 1995.

60. Sipötz J, Friedrich O, Höfer S, Benzer W, Chatsakos T, Gaul G, et al. Health related quality of life and mental distress after PCl: restoring a state of equilibrium. Health Qual Life Outcomes. 2013;11:144. https://doi.org/10. 1186/1477-7525-11-144.

61. Greimel E, Kato Y, Müller-Gartner M, Salchinger B, Roth R, Freidl W. Internal and external resources as determinants of health and quality of life. PLoS One. 2016;11(5):e0153232. https://doi.org/10.1371/journal.pone.0153232.

62. Mautner E, Ashida C, Greimel E, Lang U, Kolman C, Alton D, et al. Are there differences in the health outcomes of mothers in Europe and East-Asia? A cross-cultural health survey. Biomed Res Int. 2014;856543. https://doi.org/10. 1155/2014/856543.

63. Probst T, Stippl P, Pieh C. Changes in provision of psychotherapy in the early weeks of the COVID-19 lockdown in Austria. Int J Environ Res Public Health. 2020;17(11):3815. https://doi.org/10.3390/ijerph17113815.

64. Tullio V, Perrone G, Bilotta C, Lanzarone A, Argo A. Psychological support and psychotherapy via digital devices in Covid-19 emergency time: some critical issues. Med Leg J. 2020;88(2):73-6. https://doi.org/10.1177/ 0025817220926942.

65. Van Daele T, Karekla M, Kassianos AP, Compare A, Haddouk L, Salgado J, et al. Recommendations for policy and practice of telepsychotherapy and emental health in Europe and beyond. J Psychother Integr. 2020;30(2):16073. https://doi.org/10.1037/int0000218.

66. Prajapati N, Łaszewska A, Franco D, Ericson R, Leroy S, Lindert J, et al. What are the COVID-19 Lockdown-induced illnesses and why should European public health systems be investigating their epidemiology, treatment, and prevention? The Association of Schools of Public Health in the European Region. 2020. https://www.aspher.org/download/531/aspher-lockdowninduced-illnesses.pdf. Accessed 21 Dec 2020.

67. Middleton J, Lopes H, Michelson K, Reid J. Planning for a second wave pandemic of COVID-19 and planning for winter. A statement from the Association of Schools of Public Health in the European region. Int J Public Health. 2020;65:1525-7. https://doi.org/10.1007/s00038-020-01455-7.

68. Devaux M, Sassi F. Social disparities in hazardous alcohol use: self-report bias may lead to incorrect estimates. Eur J Pub Health. 2016;26(1):129-34. https://doi.org/10.1093/eurpub/ckv190.

69. Mulder J, de Bruijne M. Willingness of Online Respondents to Participate in Alternative Modes of Data Collection. Survey Practice. 2019;12(1). https://doi. org/10.29115/SP-2019-0001.

70. Yetter G, Capaccioli K. Differences in responses to web and paper surveys among school professionals. Behav Res Methods. 2010;42(1):266-72.

\section{Publisher's Note}

Springer Nature remains neutral with regard to jurisdictional claims in published maps and institutional affiliations. 